\title{
Quantifying in-situ gas hydrates at active seep sites in the eastern Black Sea using pressure coring technique
}

\author{
K. U. Heeschen ${ }^{1, *}$, M. Haeckel ${ }^{2}$, I. Klaucke ${ }^{2}$, M. K. Ivanov ${ }^{3}$, and G. Bohrmann ${ }^{1}$ \\ ${ }^{1}$ Research Centre Ocean Margins, Bremen, Germany \\ ${ }^{2}$ Leibniz Institute of Marine Sciences (IFM-GEOMAR), Kiel, Germany \\ ${ }^{3}$ M.V. Lomonosov Moscow State University, Moscow, Russia \\ *now at: Federal Institute for Geosciences and Natural Resources (BGR), Hannover, Germany \\ Received: 15 March 2011 - Published in Biogeosciences Discuss.: 9 May 2011 \\ Revised: 21 September 2011 - Accepted: 17 October 2011 - Published: 8 December 2011
}

\begin{abstract}
In the eastern Black Sea, we determined methane $\left(\mathrm{CH}_{4}\right)$ concentrations, gas hydrate volumes, and their vertical distribution from combined gas and chloride $\left(\mathrm{Cl}^{-}\right)$measurements within pressurized sediment cores. The total gas volume collected from the cores corresponded to concentrations of $1.2-1.4 \mathrm{~mol} \mathrm{CH}_{4} \mathrm{~kg}^{-1}$ porewater at in-situ pressure, which is equivalent to a gas hydrate saturation of $15-18 \%$ of pore volume and amongst the highest values detected in shallow seep sediments. At the central seep site, a highresolution $\mathrm{Cl}^{-}$profile resolved the upper boundary of gas hydrate occurrence and a continuous layer of hydrates in a sediment column of $120 \mathrm{~cm}$ thickness. Including this information, a more precise gas hydrate saturation of $22-24 \%$ pore volume could be calculated. This volume was higher in comparison to a saturation calculated from the $\mathrm{Cl}^{-}$profile alone, resulting in only $14.4 \%$. The likely explanation is an active gas hydrate formation from $\mathrm{CH}_{4}$ gas ebullition. The hydrocarbons at Batumi Seep are of shallow biogenic origin $\left(\mathrm{CH}_{4}>99.6 \%\right)$, at Pechori Mound they originate from deeper thermocatalytic processes as indicated by the lower ratios of $\mathrm{C}_{1}$ to $\mathrm{C}_{2}-\mathrm{C}_{3}$ and the presence of $\mathrm{C}_{5}$.
\end{abstract}

\section{Introduction}

Gas hydrates consist of water cages enclosing methane $\left(\mathrm{CH}_{4}\right)$ as the major guest molecule (Sloan and Koh, 2007). Provided the pore fluids are saturated with $\mathrm{CH}_{4}$, gas hydrates form at high pressure and low temperature conditions common at ocean depths exceeding 300-500 $\mathrm{m}$ (Sloan and Koh, 2007). Because of the difficulties to inventory marine gas hydrates, considerable controversy remains about the amount

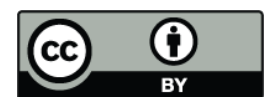

Correspondence to: K. U. Heeschen (katja.heeschen@bgr.de) and distribution of gas hydrates in marine sediments, and thus their potential as an energy resource or a contributor to past and future climate changes (e.g. Milkov et al., 2004).

On a local scale, inventory uncertainties arise from the loss of gas during core recovery, crude sampling resolution, and/or uncertain calibration of indirect methods such as acoustic detections (Dickens et al., 1997; Milkov, 2005). Porewater chloride $\left(\mathrm{Cl}^{-}\right)$anomalies are frequently used to estimate gas hydrate volumes. This is based on the exclusion of salt from the hydrate crystal lattice during hydrate formation in the sediment and the respective fresh water release when decomposition is initiated during core recovery, resulting in negative $\mathrm{Cl}^{-}$anomalies where gas hydrates had been present (e.g. Haeckel et al., 2004). However, small scale distributional variations, non-steady state conditions, and brine formation in hydrate voids contribute to uncertainties regarding these estimations, as do variations of $\mathrm{Cl}^{-}$caused by the advection of less saline fluids from depth (Haeckel et al., 2004). Pressure cores were developed within the ODP/IODP program (Dickens et al., 1997) and for coring of surface sediments (Heeschen et al., 2007; Abegg et al., 2008). They allow for determining the sediment's total in-situ $\mathrm{CH}_{4}$ inventory that is present as hydrate-bound, gaseous and dissolved $\mathrm{CH}_{4}$. This inventory then allows the calculation of the gas hydrate volume based on stability conditions and the equation of state.

Here we compare gas hydrate inventory estimates using two methods: the collection of gas from pressurized sediment cores and porewater chloride anomalies measured on the same cores. The samples originate from recently discovered seep sites off Georgia in the eastern Black Sea (Akhmetzhanov et al., 2007; Bohrmann et al., 2007). Despite gas hydrate discoveries in this area (Klaucke et al., 2006; Pape et al., 2010a) little is known about gas hydrate distributions and regional quantities in the Black Sea, the largest anoxic basin at present times (Ross and Degens, 1974). Our results

Published by Copernicus Publications on behalf of the European Geosciences Union. 
indicate that amongst the limited number of seeps that have been quantified for shallow gas hydrate volumes, the sites presented here are amongst the highest.

\section{Geological setting}

The Black Sea is an extensional basin with organic-rich sediments with porewaters of varying salinity and a total of $12-16 \mathrm{~km}$ thickness. This stack includes the thick clayrich Maikopian Unit (Ross and Degens, 1974), which is the source of numerous mud diapirs (Ross and Degens, 1974; Wagner-Friedrichs, 2007). Seep sites with $\mathrm{CH}_{4}$ gas ebullition and fluid flow are common in the Black Sea basin and lead to very high $\mathrm{CH}_{4}$ concentration in the anoxic bottom waters (Reeburgh, 2007) and widely distributed gas hydrate occurrences in the sediments (Vassilev and Dimitrov, 2002). Large numbers of gas seeps have also been discovered in the south eastern Black Sea (Klaucke et al., 2006), which is characterized by severe faulting and slumping (Ross and Degens, 1974).

Batumi (water depth: $850 \mathrm{~m}$ ) and Pechori seeps (1000 m) are located on the Kobuleti Ridge, a complex canyon-ridge system (Fig. 1), where buried diapiric structures and fault systems form migration pathways for sediments, fluids, and gases (Wagner-Friedrichs, 2007). The Batumi seep area is the largest seep site with an areal extent of $0.5 \mathrm{~km}^{2}$ characterized by shallow gas hydrates, authigenic carbonates, and vigorous gas venting (Klaucke et al., 2006; Pape et al., 2010a). Pechori Mound has $75 \mathrm{~m}$ of relief, steep slopes, and strong seafloor reflection at the top (Wagner-Friedrichs, 2007). The mound is rich in oil and massive gas hydrates. Indications for structure I gas hydrate, i.e. gas hydrates with $\mathrm{CH}_{4}$ as the prevailing guest molecule, were found at both sites (Pape et al., 2010a; S. Klapp, Univ. Bremen, personal communication, 2008).

\section{Methods}

The sediment cores originate from pressure coring operations using the Dynamic Autoclave Piston Corer (DAPC) (Abegg et al., 2008) on board RV Logachev (Akhmetzhanov et al., 2007), cruise TTR-15 (Table 1). The cores were degassed on board and subsequently sampled for porewater fluids.

\subsection{Pressure coring, gas collection and volume calculations}

The DAPC recovers a sediment core of up to $2.3 \mathrm{~m}$ length at in-situ pressure using a newly developed enhanced pressurepreserving system. Once on board, its pressure chamber is fixed upright, cooled in an ice-bath and linked to a pressure sensor, an assembly of gas-tight valves for gas subsampling, and a volumetric plastic cylinder that allows the measurement of released water and gas volumes (for details
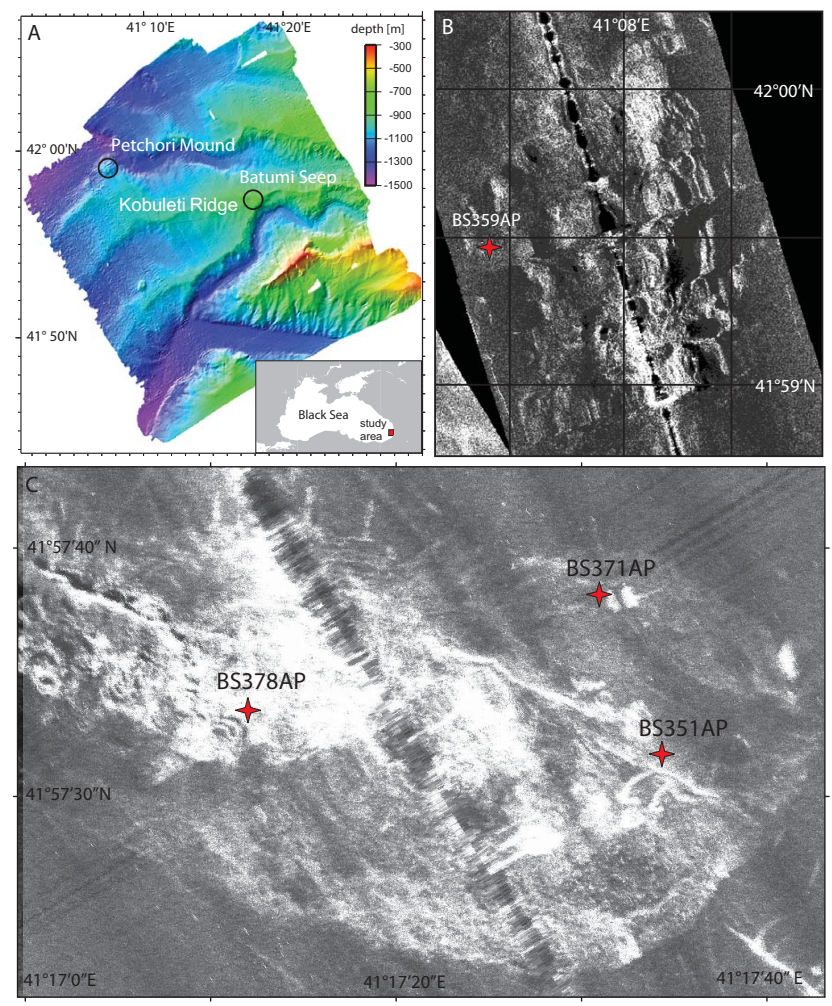

Fig. 1. Working area and coring stations (star symbols and labels) offshore Georgia, eastern Black Sea: (a) detailed bathymetric map of the study area. (b) $30 \mathrm{kHz}$ MAK Sidescan sonar mosaic of the Pechori area. (c) Detailed $75 \mathrm{kHz}$ DTS-1 sidescan sonar mosaic of the Batumi Seep. The high backscatter intensities in (b) and (c) are shown in light tones and may correlate to the presence of nearsurface gas hydrates and authigenic carbonate precipitates (modified after Klaucke et al., 2006).

see Heeschen et al., 2007). The main degassing takes several hours and is stopped when gas bubbling has ceased for several tens of minutes. When the core has warmed to ambient temperature, it is reopened to collect the small amounts of residual exsolved gas.

The gas samples were analyzed with an Agilent gas chromatograph for hydrocarbons $\mathrm{C}_{1}-\mathrm{C}_{5}$ (FID) and for oxygen, nitrogen and $\mathrm{CO}_{2}$ (TCD). Standards were: $100 \% \mathrm{C}_{1}, \mathrm{C}_{2}$, $\mathrm{C}_{3}$ and $\mathrm{CO}_{2}$, bottled mixtures of $100 \mathrm{ppm}$ and $1000 \mathrm{ppm} \mathrm{C}_{1}$ through $\mathrm{C}_{5}$ standards (in nitrogen), and air. The precision of standard measurements was $3 \%$. Contaminations of the core gas with air was measured $\left(\Sigma \mathrm{O}_{2}+\mathrm{N}_{2} ; 2-2.5 \%\right.$, Table 2) and subtracted. The hydrocarbon gas compositions are given in percentage of the sum of hydrocarbon gases $\left(\% \Sigma \mathrm{C}_{1-5}\right.$, hereafter cited as \%). The accuracy of the total gas volumes (gas/l; Table 2) is generally $5 \%$. For details see Heeschen et al. (2007).

All dissolved, free, and hydrate-bound $\mathrm{CH}_{4}\left(\Sigma \mathrm{CH}_{4} / \mathrm{mol}\right)$ was released and collected from the core during its controlled degassing. To calculate the porewater $\mathrm{CH}_{4}$ in-situ 
Table 1. Station information, sulfate depletion depth below core surface, and average core porosity.

\begin{tabular}{llllrrrr}
\hline $\begin{array}{l}\text { On Board/Pangaea } \\
\text { Station Identifier }\end{array}$ & Location & Latitude & Longitude & $\begin{array}{r}\text { Water } \\
\text { depth/m }\end{array}$ & $\begin{array}{r}\text { Core } \\
\text { length/cm }\end{array}$ & $\begin{array}{r}\text { Sulfate } \\
\text { depletion/cm }\end{array}$ & $\begin{array}{r}\text { Average } \\
\text { porosity }\end{array}$ \\
\hline BS351AP/GeoB 9909-2 & Batumi & $41^{\circ} 57.53^{\prime} \mathrm{N}$ & $41^{\circ} 17.58^{\prime} \mathrm{E}$ & 855 & 220 & $25(50)^{*}$ & 0.721 \\
BS359AP/GeoB 9913-5 & Pechori & $41^{\circ} 58.99^{\prime} \mathrm{N}$ & $41^{\circ} 07.41^{\prime} \mathrm{E}$ & 1031 & 106 & 40 & 0.680 \\
BS371AP/GeoB 9923-3 & Batumi & $41^{\circ} 57.62^{\prime} \mathrm{N}$ & $41^{\circ} 17.52^{\prime} \mathrm{E}$ & 859 & 175 & 135 & 0.705 \\
BS378AP/GeoB 9929-2 & Batumi & $41^{\circ} 57.56^{\prime} \mathrm{N}$ & $41^{\circ} 17.20^{\prime} \mathrm{E}$ & 851 & 190 & 50 & 0.721 \\
\hline
\end{tabular}

* Sediment depth of Core BS351AP was corrected $(+25 \mathrm{~cm})$ for porewater data using measurements from video guided multi coring. $220 \mathrm{~cm}$ core therefore covers $25-245 \mathrm{~cm}$ sediment depth (also see Appendix A).

Table 2. Data from gas collection including volumes of collected gas, $\mathrm{CH}_{4}$, and gas hydrate as well as dissolved and total $\mathrm{CH}_{4}$ concentrations in DAPC sediment cores between the depth of sulfate depletion and the core bottom (except BS351 AP ${ }^{85-205 \mathrm{~cm}^{2}}$ and BS351 $\mathrm{AP}^{85-205.88 \%}$ ).

\begin{tabular}{|c|c|c|c|c|c|c|c|c|c|}
\hline Station/Core & $\begin{array}{l}\text { Core } \\
\text { length } \\
\text { /cm }\end{array}$ & $\begin{array}{c}\text { Collected } \\
\text { gas } \\
/ 1\end{array}$ & $\begin{array}{l}\text { Air } \\
1 \%\end{array}$ & $\begin{array}{c}\text { Collected } \\
\mathrm{CH}_{4} \\
/ 1\end{array}$ & $\begin{array}{c}\Sigma \mathrm{CH}_{4} \\
/ \mathrm{mol} \mathrm{kg}^{-1}\end{array}$ & $\begin{array}{c}\Sigma \mathrm{CH}_{4} \\
/ \mathrm{mol}\end{array}$ & $\begin{array}{c}\mathrm{CH}_{4(\mathrm{aq})} \\
/ \mathrm{mol}\end{array}$ & $\begin{array}{l}\mathrm{GH}^{*} \\
1 \% \mathrm{pv}\end{array}$ & $\begin{array}{l}\mathrm{GH}^{*} \\
1 \% \mathrm{cv}\end{array}$ \\
\hline $\mathrm{BS} 351 \mathrm{AP}^{50-245 \mathrm{~cm}}$ & 195 & 226.2 & 2.24 & 221.0 & 1.206 & 9.03 & 0.66 & 14.6 & 10.5 \\
\hline $\mathrm{BS} 351 \mathrm{AP}^{85-205 \mathrm{~cm}}$ & 120 & 226.2 & 2.24 & 221.0 & 1.945 & 9.03 & 0.40 & 24.5 & 17.7 \\
\hline $\mathrm{BS} 351 \mathrm{AP}^{85-205.88 \%}$ & 120 & 226.2 & 2.24 & 221.0 & 1.712 & 9.03 & 0.40 & 21.5 & 15.5 \\
\hline BS359AP & 66 & 88.7 & 2.53 & 86.2 & 1.404 & 3.52 & 0.22 & 17.3 & 12.3 \\
\hline BS371AP & 45 & 10.9 & 7.16 & 10.2 & 0.234 & 0.41 & 0.15 & 1.9 & 1.6 \\
\hline BS378AP** & 140 & 200.6 & 1.96 & 196.7 & 1.425 & 8.04 & 0.49 & 17.6 & 13.3 \\
\hline
\end{tabular}

*Assuming a molar $\mathrm{CH}_{4}$ /water ratio of 5.9 in sI gas hydrates, i.e. an occupancy of $90 \%$ of the small cages by $\mathrm{CH}_{4}(\mathrm{Ussler}$ and Paull, 2001$)$, resulting in $1821 \mathrm{CH}_{4}$ per liter of gas hydrate given STP conditions ( $p=1013 \mathrm{hPa}, T=298.15 \mathrm{~K}$ ). (Note: in Heeschen et al. (2007) the $\mathrm{CH}_{4}$ volume of gas hydrate is based on $273.15 \mathrm{~K}$ and 1641 ). The $\mathrm{CH}_{4}$ equilibrium concentration $\left(c_{\mathrm{eq}}\right)$ is $0.0087 \mathrm{~mol} \mathrm{CH}_{4} \mathrm{~kg}^{-1}$.

${ }^{* *}$ A clogged valve let to difficulties while opening the liner, which caused higher uncertainties regarding the core length and thus the gas hydrate volume $(\sim 10 \%)$.

concentration in $\mathrm{mol} \mathrm{CH}_{4} \mathrm{~kg}^{-1}$ porewater (Table $2 ; \mathrm{CH}_{4} / \mathrm{mol}$ $\mathrm{CH}_{4} \mathrm{~kg}^{-1}$ ), the $\mathrm{\Sigma CH}_{4}$ is related to the amount of porewater present between the bottom of the core and the sulfate depletion depth where an even distribution of dissolved methane and hydrate-bound $\mathrm{CH}_{4}$ is assumed (Heeschen et al., 2007). We subtract the saturation concentration $\left(c_{\mathrm{eq}}\right)$ of $0.087 \mathrm{~mol} \mathrm{CH}_{4} \mathrm{~kg}^{-1}$ (Tishchenko et al., 2005; also see Appendix A) before calculating gas hydrate volumes. The molar $\mathrm{CH}_{4}$ to water ratio for the structure I gas hydrates was assumed to be 5.9, a value that was observed in natural structure I gas hydrates with an occupancy of $90 \%$ of small cages by $\mathrm{CH}_{4}$ (Ussler and Paull, 2001). All gas volumes refer to STP conditions ( 1 bar and $25^{\circ} \mathrm{C}$ ), resulting in a $\mathrm{CH}_{4}$ volume of 1821 per liter of gas hydrate.

\subsection{Gas hydrate and porewater analysis}

The gas hydrates were recovered with TV-grab (TVG) or gravity corer (GC). Clean samples were put into headspace vials that were sealed by crimping, and vented into a second vial by a vacutainer. The gas was analyzed on board (see Sect. 3.1).

The sediment of DAPC cores was sampled for porewater. In case of core BS351AP the entire core was cut into $5 \mathrm{~cm}$ thick slices. Porewater was extracted using a low-pressure squeezer $\left(<5\right.$ bar; $8{ }^{\circ} \mathrm{C}$; $0.2 \mu \mathrm{m}$ cellulose acetate Nuclepore filters) and analysed for $\mathrm{SO}_{4}^{2-}$ and $\mathrm{Cl}^{-}$using ion chromatography and Mohr titration, respectively (Wallmann et al., 2006 and references therein). IAPSO seawater standard was used for calibration. Precision of the Mohr titration was in the range of $\pm 10 \mathrm{mM} \mathrm{Cl}^{-}$. The porosity listed in Table 1 was determined by weight difference, before and after freezedrying. For the conversion into volume ratio (ratio of volume of porewater to volume of bulk sediment) we applied a dry sediment density of $2.5 \mathrm{~g} \mathrm{~cm}^{-3}$ (Haeckel et al., 2004) and a Black Sea water density of $1.021 \mathrm{~g} \mathrm{~cm}^{-3}$.

The core depths of BS351AP were corrected for the loss of surface sediments caused by heavy coring gear using porosity data from video guided multi core sampling at the same geographical coordinates (Table 1, Appendix A, Fig. A1).

\subsection{Modeling the chloride anomaly for its relation to the hydrate content}

Observed $\mathrm{Cl}^{-}$anomalies can be converted to an amount of gas hydrate in percent of the pore volume $(\mathrm{GH} / \% \mathrm{pv})$ using:

$$
\mathrm{GH}=\frac{\Delta \mathrm{Cl}}{\mathrm{Cl}_{\mathrm{ref}}} \frac{\rho_{\mathrm{PW}}}{\rho_{\mathrm{GH}}} \frac{M_{\mathrm{GH}}}{M_{\mathrm{H}_{2} \mathrm{O}}} \frac{1}{x_{\mathrm{H}_{2} \mathrm{O}}}
$$


where $\Delta \mathrm{Cl}=$ deviation of measured $\mathrm{Cl}^{-}$concentration from in-situ value $\left(\mathrm{Cl}_{\mathrm{ref}}\right), \rho_{\mathrm{PW}}=$ density of porewater, $\rho_{\mathrm{GH}}=$ density of natural hydrate, $M_{\mathrm{GH}}=$ molecular weight of methane hydrate, $M_{\mathrm{H}_{2} \mathrm{O}}=$ molecular weight of water, and $x_{\mathrm{H}_{2} \mathrm{O}}=$ molar ratio of water to methane for natural gas hydrate (Table A1). A numerical 1-D transport-reaction model (Haeckel et al., 2004) was adopted to provide the theoretical in-situ $\mathrm{Cl}^{-}$concentration profile $\left(\mathrm{Cl}_{\text {ref }}\right)$, to simulate the observed $\mathrm{Cl}$-data and the corresponding methane hydrate formation. The model was slightly extended to explicitly consider sulfate and anaerobic oxidation of methane (AOM). A complete model description can be found in Appendix A. A detailed analysis and discussion of the measured and modeled porewater data from this area was published in Reitz et al. (2011).

\section{Results and discussion}

\subsection{Highest $\mathrm{CH}_{4}$ concentrations in shallow anoxic seep sediments}

The in-situ $\mathrm{CH}_{4}$ concentrations in shallow sediments of the investigated eastern Black Sea seeps (Table 2) considerably exceeded methane saturation. Maximum gas volumes occurred at sites of very high backscatter intensity at Batumi Seep (BS378AP, 2001 and BS351AP, 2261) (Fig. 1). The shorter core, BS371AP, was taken slightly to the NE and had a smaller gas volume (111). At the central high backscatter zone of Pechori Mound core BS359 contained 881.

The gas volumes from the high reflectivity zones correspond to consistent in-situ $\mathrm{CH}_{4}$ concentrations of $1.2-$ $1.4 \mathrm{~mol} \mathrm{CH}_{4} \mathrm{~kg}^{-1}$ porewater (from here on: $\mathrm{mol} \mathrm{CH}_{4} \mathrm{~kg}^{-1}$ ) at depths below sulfate penetration (Table 2). These $\mathrm{CH}_{4}$ concentrations are $\sim 30 \%$ higher than those of surface seep sediments from the gas hydrate stability zone in the Gulf of Mexico (Heeschen et al., 2007) and the Anaximander Mountains (Mediterranean Sea, unpublished data) where maximum in-situ $\mathrm{CH}_{4}$ concentrations were about $1 \mathrm{~mol} \mathrm{CH}_{4} \mathrm{~kg}^{-1}$. Recently however, Pape et al. (2010b) reported similar concentrations in the region of the Anaximander Mountains. Concentrations from conventional and pressurized coring differ by two orders of magnitude at all sites caused by loss of $\mathrm{CH}_{4}$ during core retrieval. For example, at Batumi Seep, maximum $\mathrm{CH}_{4}$ concentrations of $0.013 \mathrm{~mol} \mathrm{CH}_{4} \mathrm{~kg}^{-1}$ were measured in conventional cores (Klaucke et al., 2006) that contained gas hydrates and had a calculated $\mathrm{CH}_{4}$ saturation $\left(c_{\mathrm{eq}}\right)$ of $0.087 \mathrm{~mol} \mathrm{CH}_{4} \mathrm{~kg}^{-1}$.

All in-situ $\mathrm{CH}_{4}$ concentrations are far above saturation. The excess $\mathrm{CH}_{4}\left(>c_{\mathrm{eq}}\right)$ is presumed to be bound in gas hydrate, which at three out of four sites occupies a rather consistent pore volume of $\sim 16.5 \%$ (\% pv) or a core volume of $12 \%(\% \mathrm{cv})$ at depths between the sulfate penetration and the core bottom (Table 2, Fig. 2a). For better comparison with published data we refer to $\%$ pv hereafter. Core BS371AP from the area of intermediate backscatter intensity contains $2 \%$ pv of gas hydrate.

Despite the low fluid advection rates at Batumi Seep of $0.1 \mathrm{~cm} \mathrm{a}^{-1}$ (see Appendix A), the gas hydrate volumes are slightly higher than the average of 5-15\% pv estimated for high gas flow sites (Milkov, 2005) distinguished by small scale structural gas hydrate accumulations and seep site characteristics. The simultaneous occurrence of high amounts of gas hydrates and widespread vigorous gas ebullition observed in the area (Klaucke et al., 2006; Nikolovska et al., 2008) suggests gas transport as the major supply for methane to form gas hydrate. Our model simulations confirm this hypothesis because neither diffusion nor the low upward advection velocities constrained for the Batumi area are able to transport sufficient amounts of methane to the surface sediments to allow for considerable hydrate formation. To form hydrate saturations comparable to the observations it is necessary to introduce an additional methane source, the dissolution of methane from rising gas bubbles.

\subsection{Gas hydrate distribution from chloride measurements}

The degassing of DAPC cores holds no information on the vertical distribution of gas hydrates in the sediment as do, e.g. high-resolution $\mathrm{Cl}^{-}$profiles commonly used on conventional cores to determine the gas hydrate distribution and quantities. A limitation of the latter application is the assumption of a linear background $\mathrm{Cl}^{-}$profile, which ignores the possibility of local $\mathrm{Cl}^{-}$enrichments from recent gas hydrate formation (Haeckel et al., 2004), i.e. non-steady state conditions, the possible presence of brines in gas hydrate voids that are not in equilibrium with the surrounding porewater, or the occurrence of free gas that leave no trace in $\mathrm{Cl}^{-}$profiles. To compare two methods of gas hydrate budgeting, we obtained a high-resolution $\mathrm{Cl}^{-}$profile in the gas-rich core, BS351AP, from Batumi Seep after degassing (Fig. $2 b$ and c). At the seep, two processes lower the $\mathrm{Cl}^{-}$concentration: (1) the upward-directed transport of Cl-depleted fluids from deeper limnic sediments (Ross and Degens, 1974) and (2) local gas hydrate decomposition, which releases Cl-depleted fluids. Combining the high-resolution $\mathrm{Cl}^{-}$profile from BS351AP and 1-D numerical transport-reaction modeling resolves both processes (Fig. 2b and c, Appendix A): upward transport determines the background profile (dotted line) whereas the decomposition of gas hydrates leads to a broad diversion (solid line) at $85-205 \mathrm{~cm}$ (depth corrected, Table 1) plus comparably small diversions at 75 and $225 \mathrm{~cm}$ that are within the precision of the $\mathrm{Cl}^{-}$measurements. Calculations using the major $\mathrm{Cl}^{-}$anomaly between $85-205 \mathrm{~cm}$ core depth result in a mean in-situ $\mathrm{CH}_{4}$ concentration of $1.04 \mathrm{~mol} \mathrm{CH}_{4} \mathrm{~kg}^{-1}$ in this depth range. This is equivalent to an average gas hydrate volume of $14.4 \%$ pv containing 1251 of $\mathrm{CH}_{4}$ gas (at STP). Including the possible $\mathrm{Cl}^{-}$anomalies above and below the interval of $85-205 \mathrm{~cm}$, the total gas volume is 140.71 , thus 


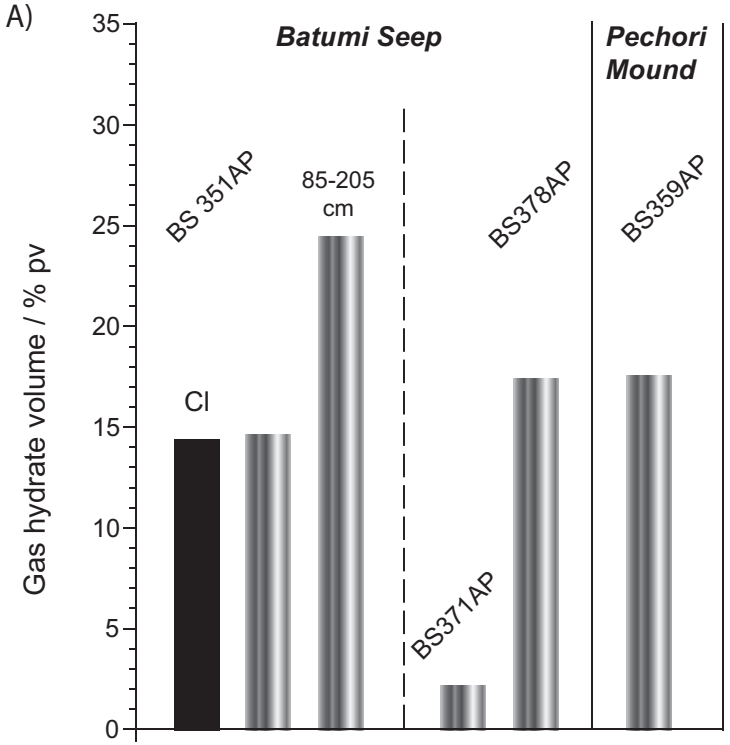

Stations with pressure core degassing

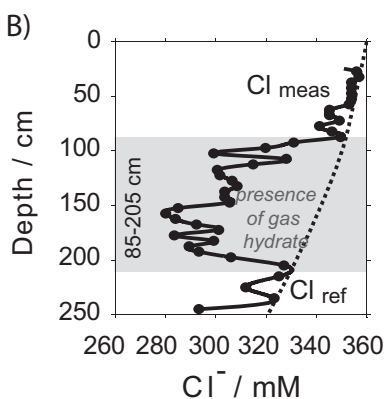

C)

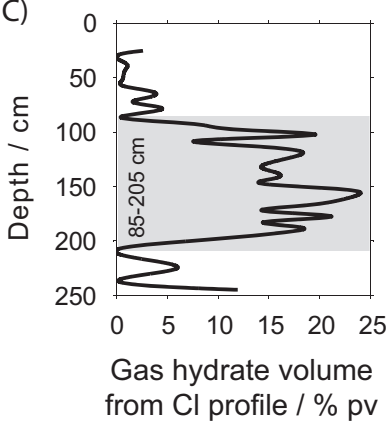

Fig. 2. (a) Gas hydrate volumes in shallow sediments of Batumi Seep and Pechori Mound as calculated from the degassing of the DAPC cores, given in per cent pore volume (\% pv). Hydrate volumes for core BS351AP are derived from the degassing (gray columns, gas), the $\mathrm{Cl}^{-}$profile model in (b) and (c) (black column, $\mathrm{Cl}$ ), and the volume (black column, comb) gained from the combined results of degassing and the chloride measurements, i.e. $2111 \mathrm{CH}_{4}$ locked in gas hydrates at core depth between 85 and $205 \mathrm{~cm}$. (b) $\mathrm{Measured}^{-} \mathrm{Cl}^{-}$concentrations of BS351AP (dots) in comparison to the modeled "in-situ" $\mathrm{Cl}^{-}$profile $\left(\mathrm{Cl}_{\mathrm{ref}}\right.$, dotted line) characterized by the advection of less saline fluids (c) Calculated gas hydrate distribution depth as calculated from $\mathrm{Cl}^{-}$anomalies and $\mathrm{Cl}_{\text {ref }}$ in core BS351AP. Sulfate depletion in core with BS351AP is reached at $75 \mathrm{~cm}$ core depth. See Methods 3.3 and Appendix for details on the model.

indicating that at most $12 \%$ of gas may originate from depths other than $85-205 \mathrm{~cm}$.

Based on the $\mathrm{Cl}^{-}$profile, the majority of gas hydrate is concentrated at $85-205 \mathrm{~cm}$ below sea floor. If the $\mathrm{CH}_{4}$ inventory gained from core degassing is corrected for this true depth range of gas hydrate occurrences, the degassed $\mathrm{CH}_{4}$ volume relates to an average $\mathrm{CH}_{4}$ concentration of $1.945 \mathrm{~mol} \mathrm{CH}_{4} \mathrm{~kg}^{-1}$ and a gas hydrate occupancy of $24 \% \mathrm{pv}$ in a layer with a thickness of $120 \mathrm{~cm}$ (Fig. 2, Table 2: BS351 $\left.\mathrm{AP}^{85-205 \mathrm{~cm}}\right)$. Assuming that a maximum of $12 \%$ of the collected gas is located outside this layer this occupancy

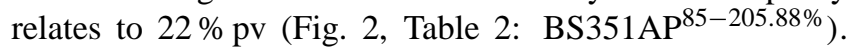
This is $7-10 \%$ above the value from Cl-based calculations.

The disparity between the methods can be explained by $\mathrm{Cl}^{-}$enriched brines forming during active gas hydrate formation. These enrichments cannot be accounted for with a steady state model, nor can they be resolved in porewater profiles of retrieved cores as they are overprinted by dilution due to (a) gas hydrate decomposition during core recovery (and degassing procedure), and (b) diffusive and, particularly, advective mixing with the lower chloride concentrations in the surrounding porewater (Haeckel et al., 2004) (Appendix A). It is unlikely that the disparity is caused by substantial amounts of free gas in the sediment, i.e. methane not bound in gas hydrates nor being dissolved. During degassing, free gas is released first, while gas hydrates remain stable. The free gas would be enriched in gas molecules excluded from gas hydrate formation or be similar to the advecting vent gas if caused by ebullition. In core BS351AP, the first 111 of the released gas are slightly enriched in ethane $\left(\mathrm{C}_{2}\right)$ (Appendix B). However, this volume only accounts for $0.5 \%$ of the gas hydrate volume, i.e. a small fraction of the disparity.

Our approach of combining both methods provides the means to greatly improve the quantification of sedimentary hydrate contents via pressure coring. While the degassing of pressurized cores resolves quantities and gas compositions, the $\mathrm{Cl}^{-}$profile holds information about the vertical gas hydrate distribution and allows to determine the boundary conditions of gas hydrate stability (Heeschen et al., 2007; Milkov et al., 2004). Further, a discrepancy between both methods is a good indicator for recent and ongoing gas hydrate formation or the presence of large volumes of free gas.

\subsection{Gas compositions derived from pressure coring}

At Batumi Seep the released hydrocarbons $\left(\Sigma_{\mathrm{C}_{1}-\mathrm{C}_{5}}\right)$ consist of $99.63 \% \mathrm{CH}_{4}$, a small contribution of ethane, and 
Table 3. Average hydrocarbon composition of the collected gas (\%) and the Bernard Ratio $\left(B_{f}\right) ;$ n.d. $=$ not detected.

\begin{tabular}{lrrrrrrr}
\hline Station, Core & $\mathrm{C}_{1} / \%$ & $\mathrm{C}_{2} / \%$ & $\mathrm{C}_{3} / \%$ & $i$ - $\mathrm{C}_{4} / \%$ & $n$ - $\mathrm{C}_{4} / \%$ & $i$ - $\mathrm{C}_{5} / \%$ & $B_{f}$ \\
\hline BS351AP & 99.966 & 0.033 & 0.001 & n.d. & n.d. & n.d. & 2940 \\
BS359AP & 99.634 & 0.274 & 0.022 & 0.055 & 0.001 & 0.007 & 337 \\
BS371AP & 99.964 & 0.024 & 0.002 & n.d. & n.d. & 0.007 & 3845 \\
BS378AP & 99.963 & 0.036 & 0.001 & n.d. & n.d. & n.d. & 2701
\end{tabular}

traces of propane, whereas at Pechori Mound $\mathrm{C}_{2}$ and $\mathrm{C}_{3}$ compositions are one order of magnitude higher and $\mathrm{C}_{4+}$ are present (Table 3). $\mathrm{CH}_{4}$ and $\mathrm{C}_{2}$ can be produced through both, the microbial (biogenic) and thermocatalytic (thermogenic) decomposition of organic matter whereas $\mathrm{C}_{3+}$ alkanes are mainly assigned to thermocatalytic reactions at greater depth (Whiticar, 1999). The ratio of methane to ethane and propane, called the Bernard Ratio $\left(B_{f}=\mathrm{CH}_{4} /\left(\mathrm{C}_{2}+\mathrm{C}_{3}\right)\right)$ is often used as an indication for a biogenic or thermogenic pathway for alkane gases (Whiticar, 1999). Batumi Seep displays $B_{f}$-values of $2700-3800$, indicating a largely biogenic origin, which is in good agreement with data from Pape et al. (2010a). At Pechori Mound, however, a $B_{f}$ of 400 and the presence of $\mathrm{C}_{4+}$ and oil strongly supports a thermogenic origin of the light hydrocarbons. This is in good agreement with porewater analysis on sediment cores from the same sites. Here $\mathrm{Li}, \mathrm{B}, \delta^{18} \mathrm{O}$ and ${ }^{87 / 86} \mathrm{Sr}$ propose a fluid source with temperatures $>100{ }^{\circ} \mathrm{C}$ from smectite-illite transformation only at Pechori Mound (Reitz et al., 2011).

The difference in gas compositions at the two sites is strongly expressed in the gas hydrate composition (Table 4). Whereas gas hydrates at Batumi Seep contain $C_{1}$ and $C_{2}$ only, the hydrate samples from Pechori Mound have a $\mathrm{C}_{2}$ to $\mathrm{C}_{3}$ ratio $<1$, often characteristic for a mixture of gas hydrate structures (Sloan and Koh, 2007). Pure methane hydrates were reported earlier at Batumi Seep (Klaucke et al., 2006; Pape et al., 2010a).

\section{Conclusions}

Combined measurements of gas volumes and high-resolution porewater chlorinity on pressurized cores allow the assessment of gas hydrate volumes, formation, distribution, and origin. At sites in the Eastern Black Sea, gas hydrate volumes in shallow sediments are among the highest values known so far with up to $24 \%$ pv. Further investigations will show whether these high gas hydrate volumes represent a local enrichment or are widely distributed in the organic-rich sediments of the anoxic Black Sea. The investigated gas hydrates at the central Batumi Seep occurred mostly at $85-205 \mathrm{~cm}$ depth and the difference between the chloride-based (140.71) and the collected (2111) $\mathrm{CH}_{4}$ gas volume indicates currently active gas hydrate formation not to be resolved from porewater data. Pure methane hydrates at Batumi Seep are fed
Table 4. Gas Hydrate Compositions from Batumi Seep Cores (BS350G: $n=4$; BS352G: $n=1$ ) and Pechori Mound (BS356G: $n=1$; BS360G: $n=3$ ); n.d. $=$ not detected.

\begin{tabular}{lrrrr}
\hline & \multicolumn{2}{c}{ Batumi Seep } & \multicolumn{2}{c}{ Pechori Mound } \\
Alkane & BS350G & BS352G & BS360G & BS356G \\
\hline $\mathrm{C}_{1} / \%$ & 99.91 & 99.71 & 99.14 & 97.63 \\
$\mathrm{C}_{2} / \%$ & 0.08 & 0.28 & 0.15 & 0.25 \\
$\mathrm{C}_{3} / \%$ & n.d. & 0.01 & 0.58 & 1.64 \\
$i-\mathrm{C}_{4} / \%$ & n.d. & n.d. & 0.10 & 0.39 \\
$n-\mathrm{C}_{4} / \%$ & n.d. & n.d. & 0.02 & 0.08 \\
\hline
\end{tabular}

by the ebullition of biogenic $\mathrm{CH}_{4}$ gas, whereas at Pechori Mound the light hydrocarbons originate from thermogenic processes.

\section{Appendix A}

\section{A1 Numerical transport-reaction modelling}

A simple 1-D transport-reaction model (Haeckel et al., 2004) was adopted to simulate the observed $\mathrm{Cl}^{-}$data and the corresponding methane hydrate formation. Four chemical species (chloride, methane, sulfate, and gas hydrate) and the porosity change due to hydrate formation were considered.

\section{A1.1 Model description}

\section{Porosity}

In early diagenetic models the porosity depth distribution, $\phi(x)$, generally does not change significantly with time, and hence, is prescribed by an empirical function fitted to the measured porosity data (Fig. A1). Gas hydrate formation reduces the porosity with time. Thus, porosity was calculated using:

$\phi(x, t)=\phi_{\infty}+\left(\phi_{0}-\phi_{\infty}\right) e^{-\beta x}-\mathrm{GH}(x, t)$

where $\phi_{0}=$ porosity at the sediment surface $(x=0)$, $\phi_{\infty}=$ porosity at infinite depth $(x=\infty)$, and $\mathrm{GH}=$ porosity reduction due to gas hydrate.

The "true" porosity of hydrate-bearing, near-surface sediments results from a combination of hydrate pieces, gas hydrates filling pore spaces, and hydrate-free sediments. In addition, hydrate pieces displace the original sediment, thus producing fractures. Despite an internal porosity close to zero, they do not seal the sediment above the hydrate layer from that below because the pieces are intercalated in the sediment matrix. This complex mechanism needs future investigation before "true" porosity calculations are feasible. For now, we approximated the porosity reduction as if hydrate formation is solely filling the pore space. We are confident that this description leads only to small errors in our results. 

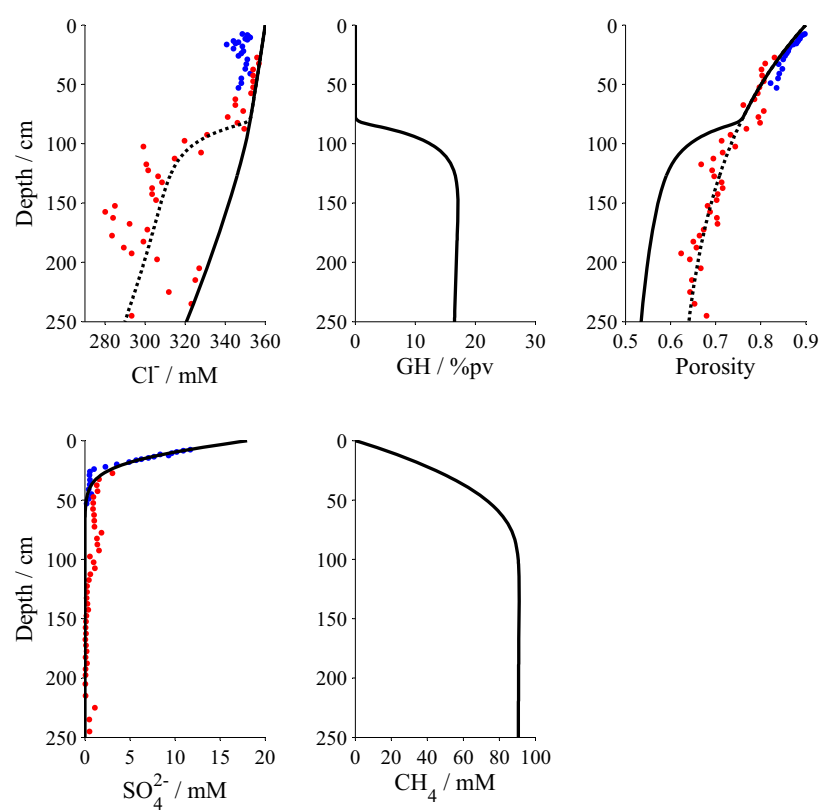

Fig. A1. Result of the numerical 1-D transport-reaction model (solid lines) of gas hydrate formation in the Batumi Seep Area at Site BS 351 DAPC. Plotted data are a combination of BS 351 DAPC (red dots) and BS $369 \mathrm{MC}$ (blue dots). The DAPC core probably lost $\sim 25 \mathrm{~cm}$ sediment at the top, as inferred from the measured porosity data, whereas the multicorer liner penetrated too deep and therefore is missing the top $7 \mathrm{~cm}$ of the sediment, as inferred from the sulfate data. The values of the adjusted model parameters of this simulation are given in Table A1. The dotted Clprofile would be observed ex-situ after decomposition of all modelpredicted methane hydrate. The dotted porosity profile represents the initial depth distribution without hydrate formation as derived from least squares fitting to the data.

\section{Advection}

Assuming steady state compaction, the burial velocity can be expressed as:

$w(x, t)=\frac{1-\phi_{\infty}}{1-\phi(x, t)} w_{\infty}$

where $w_{\infty}=$ sedimentation rate at infinite depth.

Since burial and compaction at cold vent sites are much smaller than the upward fluid flow, they can be neglected and the advection rate is:

$u(x, t)=\frac{\phi_{0}}{\phi(x, t)} u_{0}$

where $u_{0}=$ fluid flow rate at the sediment surface.

\section{Methane hydrate formation}

Methane hydrate formation is assumed proportional to the saturation state of methane in the porewater with respect to its equilibrium concentration in the presence of the hydrate phase $\left(L_{\mathrm{GH}}\right)$ :

$R_{\mathrm{GH}}=k_{\mathrm{GH}}\left(\frac{\mathrm{CH}_{4}}{L_{\mathrm{GH}}}-1\right)$

$L_{\mathrm{GH}}$ was calculated following Tishchenko et al. (2005). The kinetic constant $k_{\mathrm{GH}}$ has units of volume hydrate by bulk sediment volume and time. Hydrate formation is simulated within the entire modeled sediment column.

Since hydrate formation withdraws methane from the porewater, the rate of methane consumption (in units of mole $\mathrm{CH}_{4}$ per volume porewater and time) is related to $R_{\mathrm{GH}}$ by:

$R_{\mathrm{M}}=\frac{\rho_{\mathrm{GH}}}{M_{\mathrm{GH}} \phi} R_{\mathrm{GH}}$

where $\rho_{\mathrm{GH}}=$ density of methane hydrate and $M_{\mathrm{GH}}=$ molar weight of natural gas hydrate.

\section{Methane gas dissolution}

As gas bubbles rise through the sediments they are replenishing the porewater methane content. A first order rate accounts for this dissolution of ascending gas bubbles:

$R_{\mathrm{MB}}=k_{\mathrm{MB}}\left(L_{\mathrm{MB}}-\mathrm{CH}_{4}\right)$

where methane concentration in equilibrium with the gas phase, $L_{\mathrm{MB}}$, is calculated following Tishchenko et al. (2005). Methane gas is represented by a source term for methane dissolved in the porewater (Eqs. A6, A14). It is not transported explicitly by the model. $L_{\mathrm{GH}}$ and $L_{\mathrm{MB}}$ are kept constant during the model runs because the imposed salinity change does not alter the methane equilibrium concentrations significantly enough to affect the model results. Additionally, pressure and temperature are constant in the investigated sediment interval.

Finally, based on ROV observations of vigorous ebullition of methane gas bubbles at the seafloor, we believe that the assumption of an inexhaustible methane gas source is justified.

\section{Anaerobic oxidation of methane (AOM)}

As additional reaction affecting dissolved methane concentrations, anaerobic oxidation of methane (AOM) was included:

$\mathrm{CH}_{4}+\mathrm{SO}_{4}^{2-} \rightarrow \mathrm{HCO}_{3}^{-}+\mathrm{HS}^{-}+\mathrm{H}_{2} \mathrm{O}$

Mathematically, a second-order rate law describes this redox reaction:

$R_{\mathrm{AOM}}=k_{\mathrm{AOM}} \mathrm{CH}_{4} \mathrm{SO}_{4}^{2-}$

where $k_{\mathrm{AOM}}$ is the rate constant for AOM. 


\section{Chloride exclusion}

During methane hydrate formation chloride is excluded from the hydrate phase and added to the surrounding porewater. This mass change of porewater over time can be expressed as:

$m_{\mathrm{PW}}^{f}=m_{\mathrm{PW}}^{i}-d m_{\mathrm{GH}}$

where the indices $i$ and $f$ denote the mass of porewater before and after hydrate formation and $d m_{\mathrm{GH}}$ is the mass of the precipitated gas hydrate. Converting mass into a volume balance leads to:

$V_{\mathrm{PW}}^{f}=V_{\mathrm{PW}}^{i}-\frac{\rho_{\mathrm{GH}}}{\rho_{\mathrm{PW}}} d V_{\mathrm{GH}}$

Thus, the change in chloride concentration, $d \mathrm{Cl}$, can be written:

$$
\begin{aligned}
d \mathrm{Cl} & =\mathrm{Cl}^{f}-\mathrm{Cl}^{i}=\frac{n_{\mathrm{Cl}}^{f}}{V_{\mathrm{PW}}^{i}-\frac{\rho_{\mathrm{GH}}}{\rho_{\mathrm{PW}}} d V_{\mathrm{GH}}}-\mathrm{Cl}^{i} \\
& =\frac{n_{\mathrm{Cl}}^{i}}{V_{\mathrm{PW}}^{i}-\frac{\rho_{\mathrm{GH}}}{\rho_{\mathrm{PW}}} d V_{\mathrm{GH}}}-\mathrm{Cl}^{i}
\end{aligned}
$$

where $n_{\mathrm{Cl}}=$ amount of chloride before $(i)$ and after $(f)$ hydrate formation, and $n_{\mathrm{Cl}}^{f}=n_{\mathrm{Cl}}^{i}$, since the total mass of chloride remains constant during hydrate formation. Rearranging gives:

$d \mathrm{Cl}=\frac{\mathrm{Cl}^{i} \rho_{\mathrm{GH}} d V_{\mathrm{GH}}}{\rho_{\mathrm{PW}} V_{\mathrm{PW}}^{i}-\rho_{\mathrm{GH}} d V_{\mathrm{GH}}}=\frac{\mathrm{Cl}^{i} \rho_{\mathrm{GH}} d \mathrm{GH}}{\rho_{\mathrm{PW}} \phi^{i}-\rho_{\mathrm{GH}} d \mathrm{GH}}$

where porosity $\phi=V_{\mathrm{PW}} / V_{\text {bulkSed }}$ and $d \mathrm{GH}=d V_{\mathrm{GH}} / V_{\text {bulkSed }}$ is porosity change due to methane hydrate formation. The rate of chloride exclusion $\left(R_{\mathrm{Cl}}=d \mathrm{Cl} / d t\right)$ is related to the hydrate formation rate $\left(R_{\mathrm{GH}}=d \mathrm{GH} / d t\right)$ by:

$R_{\mathrm{Cl}}=\frac{d \mathrm{Cl}}{d t}=\frac{\mathrm{Cl} \rho_{\mathrm{GH}}}{\rho_{\mathrm{PW}} \phi-\rho_{\mathrm{GH}} d \mathrm{GH}} R_{\mathrm{GH}} \approx \mathrm{Cl} \frac{\rho_{\mathrm{GH}}}{\rho_{\mathrm{PW}} \phi} R_{\mathrm{GH}}$

where the simplification holds when $\rho_{\mathrm{GH}} d \mathrm{GH} \ll \rho_{\mathrm{PW}} \phi$ for small $d t$.

\section{Model equations}

The model's governing transport-reaction equations are:

Chloride:

$$
\begin{aligned}
\frac{\partial \phi \mathrm{Cl}}{\partial t} & =\frac{\partial}{\partial x}\left(\phi \frac{D_{\mathrm{Cl}}}{\theta^{2}} \frac{\partial \mathrm{Cl}}{\partial x}+\phi_{0} u_{0} \mathrm{Cl}\right) \\
& +\mathrm{Cl} \frac{\rho_{\mathrm{GH}}}{\rho_{\mathrm{PW}}} k_{\mathrm{GH}}\left(\frac{\mathrm{CH}_{4}}{L_{\mathrm{GH}}}-1\right)
\end{aligned}
$$

Methane:

$$
\begin{aligned}
\frac{\partial \phi \mathrm{CH}_{4}}{\partial t} & =\frac{\partial}{\partial x}\left(\phi \frac{D_{\mathrm{CH}_{4}}}{\theta^{2}} \frac{\partial \mathrm{CH}_{4}}{\partial x}+\phi_{0} u_{0} \mathrm{CH}_{4}\right) \\
& -\frac{\rho_{\mathrm{GH}}}{M_{\mathrm{GH}}} k_{\mathrm{GH}}\left(\frac{\mathrm{CH}_{4}}{L_{\mathrm{GH}}}-1\right) \\
& +\phi k_{\mathrm{MB}}\left(L_{\mathrm{MB}}-\mathrm{CH}_{4}\right) \\
& -\phi k_{\mathrm{AOM}} \mathrm{SO}_{4}^{2-} \mathrm{CH}_{4}
\end{aligned}
$$

Gas hydrate:

$$
\frac{\partial \mathrm{GH}}{\partial t}=-\frac{1-\phi_{\infty}}{1-\phi} w_{\infty} \frac{\partial \mathrm{GH}}{\partial x}+k_{\mathrm{GH}}\left(\frac{\mathrm{CH}_{4}}{L_{\mathrm{GH}}}-1\right)
$$

Sulfate:

$$
\begin{aligned}
\frac{\partial \phi \mathrm{SO}_{4}^{2-}}{\partial t} & =\frac{\partial}{\partial x}\left(\phi \frac{D_{\mathrm{SO}_{4}^{2-}}}{\theta^{2}} \frac{\partial \mathrm{SO}_{4}^{2-}}{\partial x}+\phi_{0} u_{0} \mathrm{SO}_{4}^{2-}\right) \\
& -\phi k_{\mathrm{AOM}} \mathrm{SO}_{4}^{2-} \mathrm{CH}_{4}
\end{aligned}
$$

where $D_{i}=$ diffusion coefficients of $\mathrm{Cl}^{-}, \mathrm{CH}_{4}$, and $\mathrm{SO}_{4}^{2-}$ corrected for salinity, temperature and pressure (Hayduk and Laudie, 1974; Li and Gregory, 1974), and $\theta^{2}=12 \ln \phi$ is the tortuosity correction for diffusion (Boudreau, 1997).

This set of partial differential equations was solved numerically within the MATLAB ${ }^{\circledR}$ environment. The discretization of Eqs. (A13-A16) was done using finite differences and a combination of Dirichlet and Neumann boundary conditions (see Table A1 for details). The initial conditions are based on the steady state profiles of the "no gas hydrate" condition: (i) linearly decreasing $\mathrm{Cl}^{-}$concentrations with depth, (ii) methane and sulfate profile if only anaerobic oxidation of methane is present and in equilibrium with methane gas phase, (iii) no gas hydrate, and (iv) observed porosity profile.

Five parameters were adjusted by comparing the model result with the observed data: (i) the advection rate $\left(u_{0}\right)$, (ii) the rate constant for hydrate formation $\left(k_{\mathrm{GH}}\right)$, (iii) the rate constant for gas bubble dissolution $\left(k_{\mathrm{MB}}\right)$, (iv) the rate constant for anaerobic oxidation of methane $\left(k_{\mathrm{AOM}}\right)$, and $(\mathrm{v})$ the simulation time $\left(t_{\max }\right)$.

\section{A1.2 Model results}

A sensitivity analyses was performed to constrain the values of these five fit parameters. The best fit (Fig. A1) to the observed data was achieved for low fluid advection velocities $\left(u_{0}=0.1 \mathrm{~cm} \mathrm{a}^{-1}\right)$ as the measured chloride profile does not show significant curvature, except for the hydrate related anomaly. The rate constant for anaerobic oxidation of methane $\left(k_{\mathrm{AOM}}\right)$ basically influences the increase in sedimentary hydrate content near the surface because AOM competes with hydrate formation for the available dissolved methane. A minimum AOM rate constant of $k_{\mathrm{AOM}}=0.03 \mathrm{mM}^{-1} \mathrm{a}^{-1}$ is able to resemble a steep increase as it can be inferred from the measured $\mathrm{Cl}$ anomaly. Diffusion of methane from below is only able to form very little gas hydrate. In order to build up considerable amounts of hydrate (i.e. several \% pv) an additional methane source is needed. Therefore methane gas bubble dissolution has been included in the model. This process is also required in order to deliver enough methane to the surface sediments, so that the onset of hydrate formation at a sediment depth of $\sim 85 \mathrm{~cm}$ can be resembled (see start of observed $\mathrm{Cl}$ anomaly in Fig. A1). The predicted rate constant for 
Table A1. Parameters and boundary conditions used in the numerical model.

\begin{tabular}{|c|c|}
\hline Parameter & Value \\
\hline \multicolumn{2}{|l|}{ Fixed: } \\
\hline Maximum depth of calculation & $500 \mathrm{~cm}$ \\
\hline Temperature & $8.0^{\circ} \mathrm{C}$ \\
\hline Pressure & $85.5 \mathrm{~atm}$ \\
\hline$w_{\infty}$ (sedimentation velocity) & $0.02 \mathrm{~cm} \mathrm{a}^{-1^{\mathrm{a}}}$ \\
\hline$\phi_{0}($ porosity at $x=0)$ & $0.914(7)^{\mathrm{b}}$ \\
\hline$\phi_{\infty}($ porosity at $x=\infty)$ & $0.60(2)^{\mathrm{b}}$ \\
\hline$\beta$ (porosity attenuation coefficient) & $0.008(1) \mathrm{cm}^{-1^{\mathrm{b}}}$ \\
\hline$\left[\mathrm{Cl}^{-}\right](x=0, t)$ & $360 \mathrm{mM}$ \\
\hline$\left[\mathrm{Cl}^{-}\right](x=500 \mathrm{~cm}, t)$ & $250 \mathrm{mM}$ \\
\hline$\left[\mathrm{CH}_{4}\right](x=0, t)$ & $0 \mathrm{mM}$ \\
\hline$\left[\mathrm{CH}_{4}\right](x=500 \mathrm{~cm}, t)$ & $\mathrm{L}_{\mathrm{MB}}$ \\
\hline$\left[\mathrm{SO}_{4}^{-}\right](x=0, t)$ & $18 \mathrm{mM}$ \\
\hline$\left[\mathrm{SO}_{4}^{-}\right](x=500 \mathrm{~cm}, t)$ & $0 \mathrm{mM}$ \\
\hline $\mathrm{GH}(x=0, t)$ & $0 \% \mathrm{pv}$ \\
\hline $\mathrm{dGH} /\left.\mathrm{dx}\right|_{x=500 \mathrm{~cm}, t}$ & 0 \\
\hline$L_{\mathrm{GH}}\left(\mathrm{CH}_{4}\right.$ equilibrium conc. with $\mathrm{GH}$ phase $)$ & $87 \mathrm{mM}^{\mathrm{c}}$ \\
\hline$L_{\mathrm{MB}}\left(\mathrm{CH}_{4}\right.$ equilibrium conc. with gas phase $)$ & $113 \mathrm{mM}^{\mathrm{c}}$ \\
\hline$M_{\mathrm{GH}}($ molar weight of natural $\mathrm{GH})$ & $122.3 \mathrm{~g} \mathrm{~mol}^{-1^{\mathrm{d}}}$ \\
\hline$\rho_{\mathrm{GH}}(\mathrm{GH}$ density) & $0.9 \mathrm{~g} \mathrm{~cm}^{-3^{\mathrm{d}}}$ \\
\hline$\rho_{\mathrm{PW}}$ (mean porewater density, linear $\mathrm{Cl}^{-}$profile) & $1.021 \mathrm{~g} \mathrm{~cm}^{-3^{\mathrm{e}}}$ \\
\hline \multicolumn{2}{|l|}{ Adjusted: } \\
\hline$t_{\max }($ simulation time $)$ & $500 \mathrm{a}$ \\
\hline$u_{0}$ (porewater advection velocity) & $0.1 \mathrm{~cm} \mathrm{a}^{-1}$ \\
\hline$k_{\mathrm{GH}}$ (rate constant for hydrate formation) & $0.005 \mathrm{a}^{-1}$ \\
\hline$k_{\mathrm{MB}}$ (rate constant for gas bubble dissolution) & $0.2 \mathrm{a}^{-1}$ \\
\hline$k_{\mathrm{AMO}}($ rate constant for $\mathrm{AOM})$ & $0.03 \mathrm{mM}^{-1} \mathrm{a}^{-1}$ \\
\hline
\end{tabular}

a Jørgensen et al. (2004).

$\mathrm{b}$ Results of least-squares fit to measured porosity data $\left(\chi^{2}=0.02\right)$ with $2 \sigma$ standard deviation given in brackets (last digit).

c Calculated following Tishchenko et al. (2005).

${ }^{\mathrm{d}}$ Ussler and Paull (2001).

e Calculated following Fofonoff and Millard (1983).

methane gas bubble dissolution is $k_{\mathrm{MB}}=0.2 \mathrm{a}^{-1}$. To balance this increased methane flux to the porewater and keep dissolved methane concentrations at equilibrium with the hydrate phase $\left(L_{\mathrm{GH}}=87 \mathrm{mM}\right.$, see Table A1), hydrate formation needs to proceed with a rate constant of at least $k_{\mathrm{GH}}=0.005 \mathrm{a}^{-1}$. Finally, a simulation time of several hundreds of years (i.e. here 500 a) ensures that the modeled solute concentrations $\left(\mathrm{Cl}^{-}, \mathrm{CH}_{4}\right.$, and $\left.\mathrm{SO}_{4}^{2-}\right)$ are at steady state; the solid gas hydrate profile is, of course, not at steady state after this time. For a simulation time of $500 \mathrm{yr}$, the model predicts an average hydrate concentration of $15.2 \% \mathrm{pv}$. This is in good agreement with the amount calculated from the chloride anomaly $(14.4 \% \mathrm{pv})$, but $10 \%$ less than the amount derived from the degassing method ( $24 \%$ pv). However, it is difficult to conclude an age of the Batumi Seep area from this finding, because hydrate related seeps are dynamic systems and methane fluxes can vary over time by orders of magni-

\section{BS351AP - Hydrocarbon compostion}

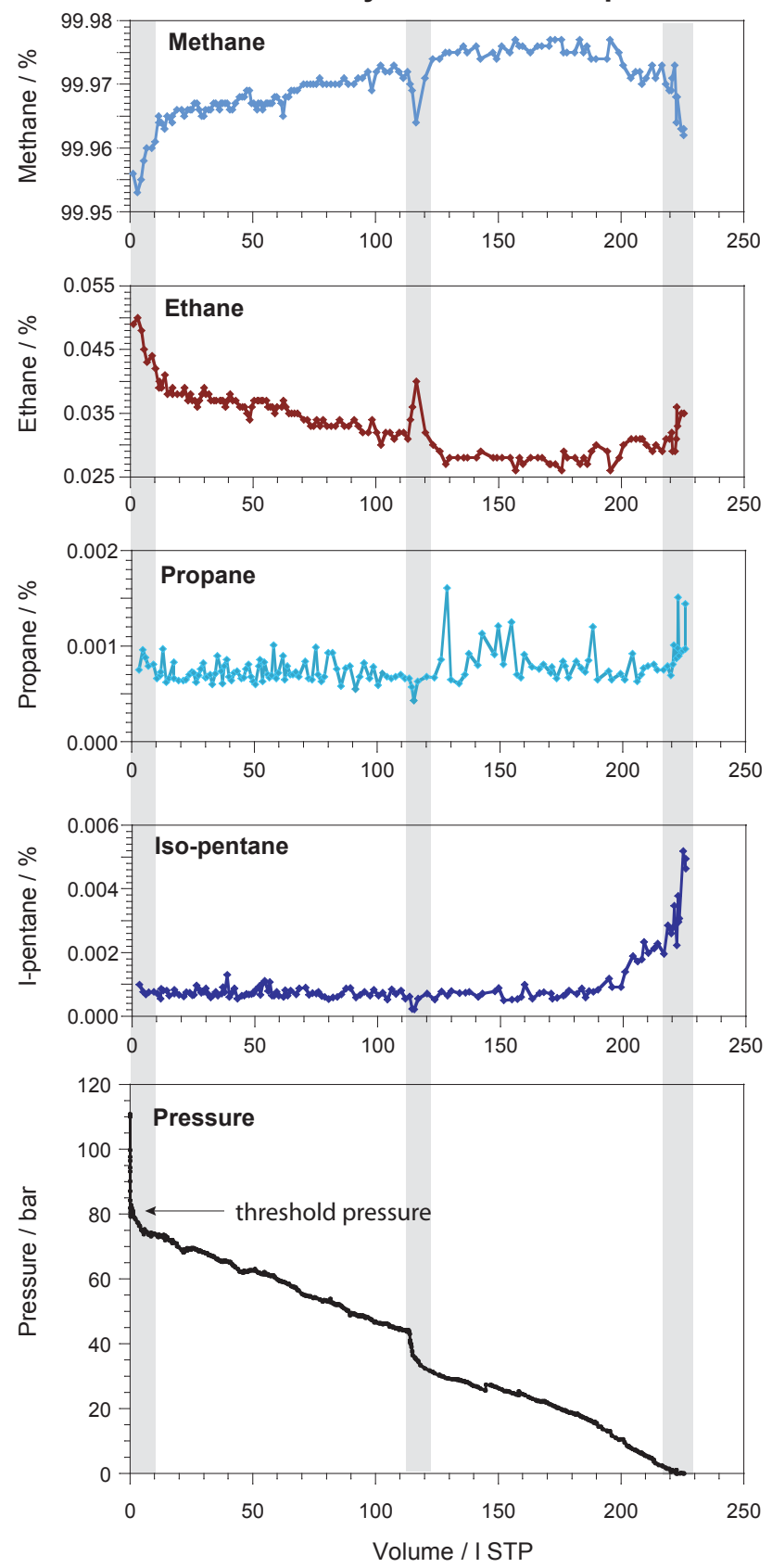

Fig. A2. Changes of gas composition (upper 4 panels) and pressure (lower panel) with increasing gas volume during the degassing of pressure core BS351AP. The gray-shaded boxes indicate areas of enhanced compositional changes, possibly due to free gas occurrences (0-111 and 112-1221) and porewater degassing (215-2261). The threshold pressure defines the onset of gas hydrate decomposition. See text for further discussion.

tude. In contrast, the model simulation assumes a constant methane flux and a constant hydrate formation rate over the entire simulation time. 


\section{A2 Degassing characteristics core BS351AP}

Methane is the main constituents of the gas collected from pressure core BS351AP with small contributions of ethane and traces of propane and i-pentane (Fig. A2). Their ratios vary only slightly $(<0.01 \%)$. The more significant alterations occur at the beginning and in the end of the degassing. At the start of the degassing (first 121) this may relate to free gas, gas hydrate of slightly different composition or ethane originating from the pore water. Free gas should be released immediately, except volumes are small and caught in the gas hydrate layer where pathways are blocked until gas hydrates start to decompose and overpressure is strong. This latter process might explain the spike occurring at about 1201. At this point opening pathways could have released a minor amount of overpressurised and encased gas leading to the pressure drop in the volume-pressure plot. Pore water degassing should release constituents that are excluded from gas hydrate structure I cages, such as i-pentane, which is clearly increasing during the last stage of the degassing, indicating pore water to degas at this point.

Degassing characteristics of the volume-pressure-time plots do not allow any conclusions regarding the distribution of free gas and gas hydrates as discussed in Dickens et al. (2000) who already pointed out that degassing at equilibrium is beyond the possibilities during a research cruise. The DAPC is too large to fit any laboratory and even so most parts of the instrument are cooled using ice, the exact temperature does not necessarily equal the in-situ temperature and is likely to vary over time and core length by a few degrees. This has implications for the gas hydrate stability and therefore the threshold pressure, which is a function of composition and temperature. The threshold pressure at in-situ temperatures $\left(8-9^{\circ} \mathrm{C}\right)$ would be 65 bar compared to 75 bar detected during degassing of BS351AP. This increase can be caused by a temperature rise of only $1-2{ }^{\circ} \mathrm{C}$. Owing to the limited information that can be gained from the available volume-pressure-plots we decided to show core BS351AP only.

Acknowledgements. Our special thanks go to: H.-J. Hohnberg, F. Abegg, B. Domeyer, K. Nass, M. Bausch, M. Reuschel, P. Behrend, the master and crew of RV Logachev and the TTR-15 onboard party. We are very thankful for the very constructive reviews of Walter S. Borowski on an earlier version of the manuscript, John Pohlman and an anonymous reviewer. Financial support was granted by the German Research Foundation, the German Ministry of Education and Research (project METRO, 03G0604A) and the German Ministry of Economy \& Technology (project SUGAR, 03SX250). This is publication GEOTECH-1554 of R\&D program GEOTECHNOLOGIEN, funded by the German Ministry of Education and Research (BMBF) and the German Research Foundation (DFG).

Edited by: T. Treude

\section{References}

Abegg, F., Hohnberg, H.-J., Pape, T., Bohrmann, G., and Freitag, J.: Development and application of pressure-core-sampling systems for the investigation of gas- and gas-hydrate-bearing sediments, Deep-Sea Res. Pt I, 55, 1590-1599, 2008.

Akhmetzhanov, A. M., Ivanov, M. K., Kenyon, N. H., Mazzini, A., and Cruise participants: Deepwater cold seeps, sedimentary environments and ecosystems of the Black and Tyrrhenian Seas and Gulf of Cadiz, UNESCO, 99, 2007.

Bohrmann, G., Pape, T., and cruise participants: Report and preliminary results of R/V Meteor cruise M72/3, Istanbul-TrabzonIstanbul, 17 March-23 April, 2007. Marine gas hydrates of the Eastern Black Sea, University of Bremen, Bremen, 2007.

Boudreau, B. P.: Diagenetic Models and Their Implementation: Modelling Transport and Reactions in Aquatic Sediments, Springer-Verlag, Berlin, Heidelberg, New York, 414 pp., 1997.

Dickens, G. D., Paull, C. K., Wallace, P., and Party, O. L. S.: Direct measurement of in situ methane quantities in a large gas-hydrate reservoir, Nature, 385, 426-428, 1997.

Dickens, G. D., Wallace, P. J., Paull, C. K., and Borowski, W. S.: Detection of methane gas hydrate in pressure core sampler (PCS): volume-pressure-time relations during controlled degassing experiments in: Proceedings of the Ocean Drilling Program, Scientific Results, edited by: Paull, C. K., Wallace, P. J., and Dillon, W. P., ODP, College Station, TX, USA, 2000.

Fofonoff, N. P./ and Millard, R. C.: Algorithms for computation of fundamental properties of seawater, Unesco Technical Papers in Marine Science, 44, 1-53, 1983.

Haeckel, M., Suess, E., Wallmann, K., and Rickert, D.: Rising methane gas bubbles form massive hydrate layers at the seafloor, Geochim. Cosmochim. Ac., 68, 4335-4345, 2004.

Hayduk, W. and Laudie, H.: Prediction of diffusion coefficients for nonelectrolytes in dilute aqueous solutions, American Institute of Chemical Engineers Journal, 20, 611-615, 1974.

Heeschen, K. U., Hohnberg, H.-J., Abegg, F., Drews, M., Haeckel, M., and Bohrmann, G.: In-situ hydrocarbon inventory from pressurized cores in surface sediments, Northern Gulf of Mexico, Mar. Chem., 107, 498-515, 2007.

Jørgensen, B. B., Böttcher, M. E., Lüschen, H., Neretin, L. N., and Volkov, I. I.: Anaerobic methane oxidation and a deep $\mathrm{H}_{2} \mathrm{~S}$ sink generate isotopically heavy sulfides in Black Sea sediments, Geochim. Cosmochim. Ac., 68, 2095-2118, 2004.

Klaucke, I., Sahling, H., Weinrebe, W., Blinova, V., Bürk, D., Lursmanashvili, N., and Bohrmann, G.: Acousitc investigation of cold seeps offshore Georgia, eastern Black Sea, Mar. Geol., 231, 51-67, 2006.

Li, Y.-H. and Gregory, S.: Diffusion of ions in sea water and in deep-sea sediments, Geochim. Cosmochim. Ac., 38, 703-714, 1974.

Milkov, A. V.: Molecular and stable isotope compositions of natural gas hydrates: A revised global dataset and basic interpretations in the context of geological settings, Org. Geochem., 36, 681-702, 2005.

Milkov, A. V., Dickens, G. D., Claypool, G. E., Lee, Y. J., Borowski, W. S., Torres, M. E., Xu, W., Tomaru, H., Tréhu, A. M., and Schultheiss, P.: Co-existence of gas hydrate, free gas, and brine within the regional gas hydrate stability zone at Hydrate Ridge (Oregon margin): evidence from prolonged degassing of a pressurized core, Earth Planet. Sc. Lett., 222, 829-843, 2004. 
Nikolovska, A., Sahling, H., and Bohrmann, G.: Hydroacoustic methodology for detection, localization, and quantification of gas bubbles rising from the seafloor at gas seeps from the eastern Black Sea, Geochem. Geophy. Geosy., 9, Q10010, doi:10.1029/2008GC002118, 2008.

Pape, T., Bahr, A., Rethemeyer, J., Kessler, J. D., Sahling, H., Hinrichs, K.-U., Klapp, S. A., Reeburgh, W. S., and Bohrmann, G.: Molecular and isotopic partitioning of low-molecular-weight hydrocarbons during migration and gas hydrate precipitation in deposits of a high-flux seepage site, Chem. Geol., 269, 350-363, 2010a.

Pape, T., Kasten, S., Zabel, M., Bahr, A., Abegg, F., Hohnberg, H.J., and Bohrmann, G.: Gas hydrates in shallow deposits of the Amsterdam mud volcano, Anaximander Mountains, Northeastern Mediterranean Sea, Geo-Mar. Lett., 30, 187-206, 2010 b.

Reeburgh, W. S.: Oceanic Methane Biogeochemistry, Chem. Rev., 107, 486-513, doi:10.1021/cr050362v, 2007.

Reitz, A., Pape, T., Haeckel, M., Schmidt, M., Berner, U., Scholz, F., Liebetrau, V., Aloisi, G., Weise, S. M., and Wallmann, K.: Sources of fluids and gases expelled at cold seeps offshore Georgia, eastern Black Sea, Geochim. Cosmochim. Ac., 75, 32503268, 2011.

Ross, D. A. and Degens, E. T.: Recent sediments of Black Sea, in: The Black Sea - geology, chemistry and biology, edited by: Ross, D. A. and Degens, E. T., AAPG, Tulsa, USA, 183-199, 1974.
Sloan, E. D. and Koh, C. A.: Clathrate Hydrates of Natural Gases, CRC Press, Boca Raton, 752 pp., 2007.

Tishchenko, P., Hensen, C., Wallmann, K., and Wong, C. S.: Calculation of the stability and solubility of methane hydrate in seawater, Chem. Geol., 219, 37-52, 2005.

Ussler, W. and Paull, C. K.: Ion exclusion associated with marine gas hydrate deposits, in: Natural Gas Hydrates - Occurrence, distribution, and detection, edited by: Dillon, W. P. and Paull, C. K., AGU, Washington, DC, 41-51, 2001.

Vassilev, A. and Dimitrov, L.: Spatial and quantity evaluation of the Black Sea gas hydrates, Geol. Geofiz., 43, 672-684, 2002.

Wagner-Friedrichs, M.: Seafloor seepage in the Black Sea: Mud volcanoes, seeps and diapiric structures imaged by acoustic methods, PhD thesis, Department of Geosciences, Univ. of Bremen, Bremen, 154 pp., 2007.

Wallmann, K., Drews, M., Aloisi, G., and Bohrmann, G.: Methane discharge into the Black Sea and global ocean via fluid flow through submarine mud volcanoes, Earth Planet. Sc. Lett., 248, 544-559, 2006.

Whiticar, M. J.: Carbon and hydrogen isotope systematics of bacterial formation and oxidation of methane, Chem. Geol., 161, 291-314, 1999. 